\title{
Outcome after intracranial haemorrhage from dural arteriovenous fistulae; a systematic review and case-series
}

\author{
W. M. T. Jolink ${ }^{1}$ (D) J. M. C. van Dijk ${ }^{3}$ - C. J. J. van Asch ${ }^{1}$ - G. A. P. de Kort ${ }^{2}$ • \\ A. Algra $^{1,5}$ - R. J. M. Groen ${ }^{3}$ G. J. E. Rinkel ${ }^{1}$ C. J. M. Klijn ${ }^{1,4}$
}

Received: 2 June 2015/Revised: 3 September 2015 / Accepted: 4 September 2015/Published online: 26 September 2015

(C) The Author(s) 2015. This article is published with open access at Springerlink.com

\begin{abstract}
Dural arteriovenous fistulae (DAVFs) are a rare cause of intracranial haemorrhage. We aimed to investigate outcome of patients with intracranial haemorrhage from a DAVF. We performed a systematic literature search for studies reporting outcome after intracranial haemorrhage caused by a DAVF. We used predefined selection criteria and assessed the quality of the studies. In addition, we studied outcome in all patients with DAVF who had presented with intracranial haemorrhage at two university centers in the Netherlands, between January 2007 and April 2012. We calculated case fatality and proportions of patients with poor outcome (defined as modified Rankin Scale $\geq 3$ or Glasgow Outcome Scale $\leq 3$ ) during followup. We investigated mean age, sex, mid-year of study and percentage of patients with parenchymal haemorrhage as determinants of case fatality and poor outcome. The
\end{abstract}

Electronic supplementary material The online version of this article (doi:10.1007/s00415-015-7898-x) contains supplementary material, which is available to authorized users.

W. M. T. Jolink

w.jolink@umcutrecht.nl

1 Department of Neurology and Neurosurgery, Brain Center Rudolf Magnus, University Medical Center Utrecht, Utrecht, The Netherlands

2 Department of Radiology, University Medical Center Utrecht, Utrecht, The Netherlands

3 Department of Neurosurgery, University Medical Center Groningen, University of Groningen, Groningen, The Netherlands

4 Department of Neurology, Donders Institute for Brain Cognition \& Behaviour, Center for Neuroscience, Radboud University Medical Center, Nijmegen, The Netherlands

5 Julius Center for Health Sciences and Primary Care, University Medical Center Utrecht, Utrecht, The Netherlands literature search yielded 16 studies, all but two retrospective and all hospital-based. Combined with our cohort of 29 patients the total number of patients with DAVF-related intracranial haemorrhage was $326(58 \%$ intracerebral haemorrhage). At a median follow-up of 12 months case fatality was $4.7 \%$ (95\% CI $2.5-7.5 ; 17$ cohorts) and the proportion of patients with poor outcome $8.3 \%(95 \% \mathrm{CI}$ 3.1-15.7; nine cohorts). We found no effect of mean age, sex, mid-year of the cohorts and percentage of patients with parenchymal haemorrhage on either outcome. Hospital based case-series suggest a relatively low risk of death and poor outcome in patients with intracranial haemorrhage due to rupture of a DAVF. These risks may be underestimated because of bias.

Keywords Dural arteriovenous fistula $\cdot$ Intracranial haemorrhage · Outcome

\section{Introduction}

Dural arteriovenous fistulae (DAVFs) are rare vascular lesions with a detection rate of $0.16 / 100,000$ adults per year [1]. They represent 10 to $15 \%$ of all intracranial vascular malformations [2]. About $20 \%$ of patients with a DAVF present with intracranial haemorrhage $[1,3]$, which is in most patients associated with venous outflow from the DAVF into a cortical vein (cortical venous reflux) [4-7].

Information on outcome after intracranial haemorrhage due to a DAVF is limited due to the rarity of the lesions. In patients with intracerebral haemorrhage (ICH) due to rupture of an arteriovenous malformation (AVM), the risk of poor outcome (modified Rankin Scale $(\mathrm{mRS}) \geq 3$ ) is lower than after spontaneous ICH, even after taking into account predictors of outcome including age [8]. It is unclear 
whether outcome after ICH due to DAVF is similar to outcome after a rupture of an AVM or comparable to outcome after spontaneous ICH.

We aimed to investigate outcome after DAVF-related intracranial haemorrhage by a systematic review of the literature and studying a case-series in two tertiary referral centers in the Netherlands.

\section{Patients and methods}

\section{Systematic literature search}

We performed a systematic literature search using PubMed and Embase for studies of patients with a DAVF-related intracranial haemorrhage from January 1980 to April 2015 (Supplementary Fig. 1) according to the PRISMA statement methodology [9]. We used different combinations of 'h(a)emorrhage' or 'hematoma' and 'dural arteriovenous fistula' and its synonyms (see Supplementary Table 1 for details of the search strategy). References of included articles, related citations and relevant reviews were screened for additional articles. After filtering duplicates, articles were screened by one reviewer (WMTJ) on title and abstract using predefined inclusion and exclusion criteria. Inclusion criteria were: (1) sample size of at least ten patients with DAVF-related intracranial haemorrhage; (2) the diagnosis of DAVF had to be proven by digital subtraction angiography in at least $90 \%$ of patients; (3) follow-up of at least one month; (4) if a study reported not only patients with DAVF-related intracranial haemorrhage but also other presenting symptoms, it had to be possible to extract data on outcome for the patients with DAVF-related intracranial haemorrhage separately. We excluded study cohorts when more than $10 \%$ of the fistulae were located at the cavernous sinus, because these lesions have a different etiology, more commonly a traumatic cause, a mostly benign presentation, without intracranial haemorrhage, and a low rate of cortical venous reflux $[10,11]$. We defined a study as high quality based on predefined criteria, namely, prospective, population-based, patients with intracranial haemorrhage as inception cohort, and clearly defined outcome measures (mRS or Glasgow Outcome Scale (GOS)). Two investigators (WMTJ and CJJvA) independently extracted data on study characteristics as summarized in Table 1 and Supplementary Table 2. In case of multiple publications from one cohort, we included the most suitable publication. We defined poor outcome as a $m R S \geq 3$ or GOS $\leq 3$. If a study used other outcome measures, we extracted data on patients with poor outcome or death according to the definition of the authors. Discrepancies in extracted data between the two investigators were dissolved by a third author (CJMK).

\section{Cohort study}

From the prospectively kept Utrecht Stroke Database, including all patients with ischaemic stroke and intracerebral haemorrhage, and the Subarachnoid Haemorrhage Database, we retrieved all patients with first DAVF-related intracerebral (ICH), intraventricular (IVH) or subarachnoid haemorrhage (SAH), who presented to the University Medical Center Utrecht, the Netherlands, between January 2007 and April 2012. At the University Medical Center Groningen we retrieved data on patients from a prospectively kept neurovascular database, which we crosschecked with patient discharge records. We retrieved data on all patients with first DAVF-related intracranial haemorrhage who presented between January 2007 and January 2012.

For all patients baseline characteristics were collected as listed in Supplementary Table 2. We reviewed imaging

Fig. 1 Case fatality with $95 \%$ CI after DAVF-related intracranial haemorrhage

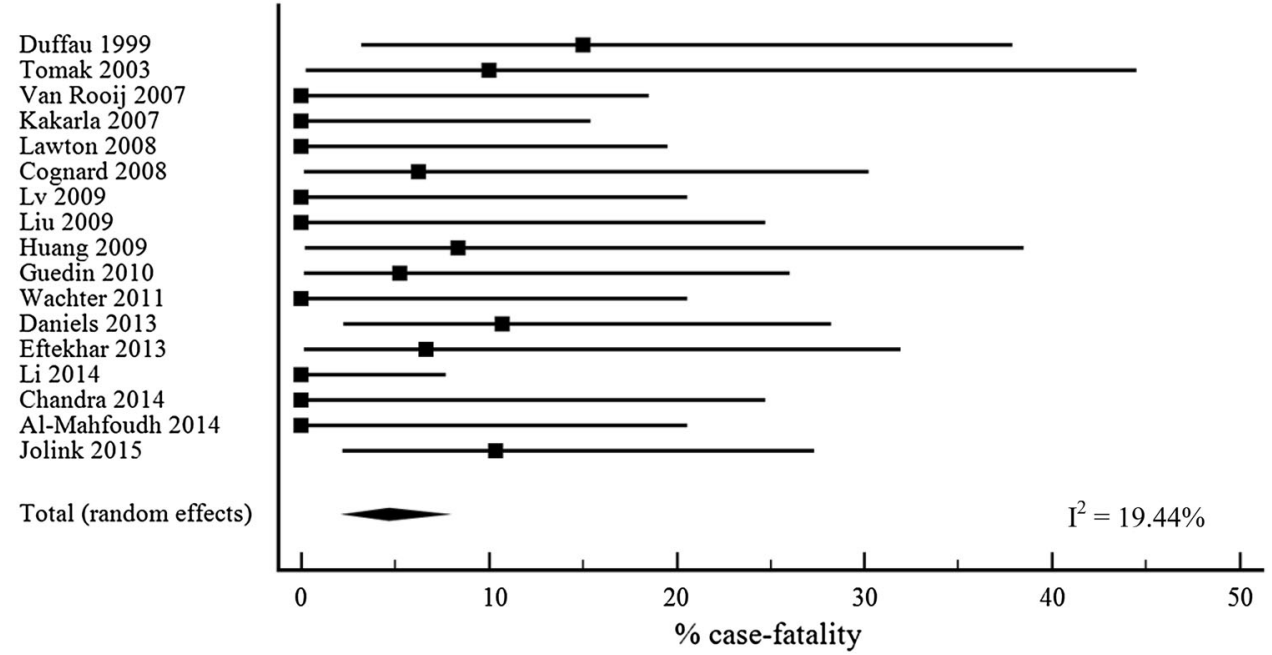


Table 1 Characteristics of cohorts of patients with DAVF-related intracranial haemorrhage

\begin{tabular}{|c|c|c|c|c|c|}
\hline References & Design & $\begin{array}{l}\text { Patients with DAVF-related } \\
\text { intracranial haemorrhage }(n)\end{array}$ & $\begin{array}{l}\text { Duration of FU } \\
\text { (months, range) }\end{array}$ & $\begin{array}{l}\text { Case fatality } \\
(\%, 95 \% \mathrm{CI})\end{array}$ & $\begin{array}{l}\text { Poor outcome } \\
(\%, 95 \% \mathrm{CI})\end{array}$ \\
\hline Duffau et al. [15] & $\mathrm{RS}$ & 20 & $10(0.3-25)$ & $15(3.2-38)$ & NR \\
\hline Tomak et al. [16] & $\mathrm{RS}$ & 10 & $11.5(1-123)$ & $10(0.3-45)$ & $10(0.3-45)$ \\
\hline Van Rooij et al. [17] & $\mathrm{RS}$ & 18 & $1.5-3$ & $0(0-19)$ & NR \\
\hline Kakarla et al. [18] & $\mathrm{RS}$ & 22 & $12(0-84)$ & $0(0-15)$ & $0(0-15)$ \\
\hline Lawton et al. [19] & $\mathrm{RS}$ & 17 & $50(1-108)$ & $0(0-20)$ & $0(0-20)$ \\
\hline Cognard et al. [20] & PS & 16 & 3 & $6.3(0.2-30)$ & NR \\
\hline Lv et al. [21] & $\mathrm{RS}$ & 16 & $8(1-16)$ & $0(0-21)$ & $0(0-21)$ \\
\hline Liu et al. [22] & $\mathrm{RS}$ & 13 & $45(2-84)$ & $0(0-25)$ & $0(0-25)$ \\
\hline Huang et al. [23] & $\mathrm{RS}$ & 12 & $3-24$ & $8.3(0.2-39)$ & $8.3(0.2-39)$ \\
\hline Guedin et al. [24] & $\mathrm{RS}$ & 19 & $3-6$ & $5.3(0.1-26)$ & NR \\
\hline Wachter et al. [25] & $\mathrm{RS}$ & 16 & $50(2-120)$ & $0(0-21)$ & NR \\
\hline Daniels et al. [26] & $\mathrm{RS}$ & 28 & 17 & $10.7(2.3-28)$ & $28.6(13-49)$ \\
\hline Eftekhar and Morgan [27] & $\mathrm{RS}$ & 15 & $18(2-82)$ & $6.7(0.2-32)$ & NR \\
\hline Li et al. [28] & RS & 46 & 20 & $0(0-8)$ & $13(5-26)$ \\
\hline Chandra et al. [29] & $\mathrm{RS}$ & 13 & $28(12-63)$ & $0(0-25)$ & NR \\
\hline Al-Mahfoudh et al. [30] & PS & 16 & $67(24-102)$ & $0(0-21)$ & NR \\
\hline Jolink (2015) & RS & 29 & $5(0-12)$ & $10(2.2-27)$ & $14(3.9-32)$ \\
\hline
\end{tabular}

$C I$ confidence interval, $D A V F$ dural arteriovenous fistula, $F U$ follow-up, $N R$ not reported specifically for patients with a DAVF presenting with intracranial haemorrhage, $P S$ prospective study design, $R S$ retrospective study design

studies for location and extension of haemorrhage (intracerebral, subarachnoid, subdural or intraventricular, or a combination of these) and location of the DAVF and we classified DAVF's according to Borden-Shucart (GAPdK and JMCvD) [4]. The diagnosis of DAVF had to be proven by digital subtraction angiography. For each patient with an ICH we calculated the ICH score consisting of known predictors of poor outcome after ICH [12]. The ICH score is the sum of individual points assigned as follows: Glasgow Coma Scale (GCS) (3-4 = 2 points, 5-12 = 1 point, $13-15=0$ points $)$, age $(\geq 80$ years $=1$ point, $<80$ years $=0$ points), infratentorial origin (yes $=1$ point, no $=0 \quad$ points $), \quad$ ICH volume $\quad\left(\geq 30 \mathrm{~cm}^{3}=1\right.$ point, $<30 \mathrm{~cm}^{3}=0$ points) and presence of IVH (yes $=1$ point, no $=0$ points). We calculated $\mathrm{ICH}$ volume $(\mathrm{mL})$ on brain imaging at presentation with the $\mathrm{ABC} / 2$ formula [13, 14]. In addition we retrieved information on death and poor functional outcome after at least one month. We defined poor outcome as a $\mathrm{mRS} \geq 3$.

\section{Statistical analysis}

We calculated mean age, proportion of males, proportion of patients with an intracerebral component of the haemorrhage, average intracerebral haemorrhage volume (for patients with ICH), follow-up period, and proportion of patients who died or had a poor outcome with corresponding $95 \%$ confidence intervals (CIs) during follow-up of at least one month. In the cohort study we performed univariate analysis of age, male sex, ICH volume $>30 \mathrm{~mL}$, and presence of a parenchymal component of the haemorrhage for case fatality and poor outcome with Cox proportional hazards analysis, resulting in hazard ratios (HR) with $95 \%$ CIs.

Proportions of patients with case fatality or poor outcome were pooled using MedCalc for Windows, version 12.7 (MedCalc Software, Ostend, Belgium). Heterogeneity between studies was calculated with the $\mathrm{I}^{2}$ statistic. To investigate the association of mid-year of study, mean age, percentage of males and percentage of patients with an parenchymal component of the haemorrhage in the study cohorts with the proportion of patients with case fatality or poor outcome, we performed linear regression analysis weighted by the inverse standard error.

\section{Results}

The literature search yielded sixteen studies that described a total of 576 patients of whom 297 patients had a DAVFrelated intracranial haemorrhage (Table 1) [15-30]. Two studies had a prospective design [20,30]; all studies were hospital-based, and none fulfilled all the criteria for highquality study. In all studies DAVFs were proven with angiography in $100 \%$ of patients.

Three studies described patients with haemorrhagic presentation only $[15,26,28]$, whereas all other studies were not restricted to patients with ruptured DAVF, but 
rather descriptions of cohorts of patients with DAVF irrespective of their presenting symptoms or treatment. One study described symptomatic DAVFs [16], ten studies described DAVFs treated by a specific modality (surgery, six studies [18, 19, 22, 25, 27, 30], endovascular treatment, four studies [20,21, 23, 29]), and two studies specifically described patients with DAVFs with cortical venous reflux $[17,24]$.

Four studies used the mRS [19, 21, 26, 28], three studies the GOS $[16,18,22]$ and one study described clinical outcome in terms of excellent, good and death [23]. Eight studies did not report on functional outcome. Information concerning cortical venous reflux, ICH volume and ICH score was not reported in most of the studies. Duration of follow-up varied between studies (Table 1). In the caseseries, all patients with DAVF-related intracranial haemorrhage were included after their first haemorrhage; in two studies, a total of eight patients had a rebleed before treatment and outcome assessment [23, 28].

In the cohort study we included 29 patients; three patients died during follow-up (Supplementary Table 2). One patient ( $3 \%)$ had a Borden-Shucart type 1 lesion, nine patients (31\%) a type 2 lesion and 19 patients $(66 \%)$ a type 3 DAVF. Eighteen patients presented with intracerebral haemorrhage. ICH volumes ranged between 0.2 and $46 \mathrm{ml}$. Five patients had an ICH score of $0(28 \%)$, six of 1 $(33 \%)$, three of $2(17 \%)$, three patients had an ICH score of $3(17 \%)$ and one patient of $4(6 \%)$. During follow-up none of the patients with an ICH score of 0,1 or 2 died. One patient with an ICH score of 3 and one patient with an ICH score of 4 died. Two patients with an intracerebral haemorrhage had a poor functional outcome (both patients died). Eleven patients presented with a SAH or IVH or a combination; one patient with a SAH died during followup. Two patients with a SAH or IVH had a poor functional outcome (one died and the other had a mRS of 3).

We found no associations with case fatality for age (HR 1.2, $95 \%$ CI 0.96-1.4), male sex (HR 0.4, $95 \%$ CI $0.03-3.9$ ), ICH volume $>30 \mathrm{~mL}$ (HR 6.1, $95 \%$ CI 0.4-99.3), and a parenchymal component of the haemorrhage (HR 1.3, $95 \%$ CI 0.1-14.3). We also found no associations for poor outcome (data not shown).

Combining the data from the literature search and our series, we had information on 326 patients with a DAVFrelated intracranial haemorrhage. The median age in all study cohorts, including our own, was 54 years (interquartile range (IQR) 51-59 years). The median proportion of men was $73 \%$ (IQR 63-84\%). Eleven studies with a total of 246 patients reported the location of the intracranial haemorrhage: ICH 161 (58 \%), SAH 69 (25\%), SDH $16(6 \%)$, IVH 31 (11\%). In 31 patients the haemorrhage was located in two or more of these compartments.
Treatment modality was not reported specifically for patients with DAVF-related intracranial haemorrhage in most studies. In the total group of 567 patients included in the studies, a total of 556 treatments was performed during follow-up: 388 patients underwent endovascular treatment, 287 patients surgery, 13 patients radiosurgery and 132 patients received multiple treatment modalities. Eleven patients were not treated at all.

Median follow-up for all patients was 12 months (IQR 7-37 months). In the five studies that specified the duration of follow-up specifically for patients with intracranial haemorrhage $[15,23,26,28]$, the median duration of follow-up was 10 months (IQR 6-19 months). The proportion of patients lost to follow-up varied from $0 \%$ to $27 \%$.

Case fatality after DAVF-related haemorrhage was $4.7 \%$ (95 \% CI 2.5-7.5, 17 cohorts, Fig. 1) [15-30] and the proportion of patients with poor outcome $8.3 \%(95 \% \mathrm{CI}$ 3.1-15.7; 9 cohorts; Fig. 2) [16, 18, 19, 21-23, 26, 28]. We did not find a statistically significant effect on case fatality for mid-year of the study ( $\beta-0.3,95 \% \mathrm{CI}-0.8$ to 0.2 ), for mean age ( $\beta 0.2,95 \% \mathrm{CI}-0.4$ to 0.7$)$, for percentage of males ( $\beta$ 0.04, (95\% CI -0.2 to 0.3 ) or for percentage of patients with an intracerebral component of the intracranial haemorrhage ( $\beta-0.1$ (95\% CI -0.2 to 0.1 ). In addition, we found no effect on poor outcome (mid-year of study $\beta 0.4$, $95 \% \mathrm{CI}-1.1$ to 2.0 ; mean age $\beta 0.4,95 \% \mathrm{CI}-1.1$ to 2.0 ; percentage of males $\beta 0.4,95 \% \mathrm{CI}-0.3$ to 1.1 ; percentage of patients with an intracerebral component of the intracranial haemorrhage $\beta 0.1,95 \% \mathrm{CI}-0.3$ to 0.5 ).

\section{Discussion}

Hospital based case-series suggest a relatively low risk of death and poor outcome in patients with intracranial haemorrhage due to rupture of a DAVF. We found no association of mid-year of studies, mean age, percentage of males, or percentage of patients with an intracerebral component of the haemorrhage with these outcomes.

In population-based cohorts, patients with an ICH due to an AVM have a risk of death of $12 \%$ after 6 months and of poor outcome at one year of $40 \%$ [8]. This risk is much lower than the reported risk after spontaneous ICH with a risk of death after 6 months of $56 \%$ and of poor outcome at 12 months of $83 \%$ [8]. A possible reason why we found lower estimates of the risk of death and poor outcome for patients with intracranial haemorrhage due to a DAVF is that the studies on which we based our estimates were all hospital based and may therefore have been influenced by referral bias, resulting in underestimation of the proportion of patients with poor outcome. Another explanation may be that in patients with a fatal or severely disabling intracranial haemorrhage due to DAVF rupture, investigations to 
Fig. 2 Poor outcome with $95 \%$ CI after DAVF-related intracranial haemorrhage

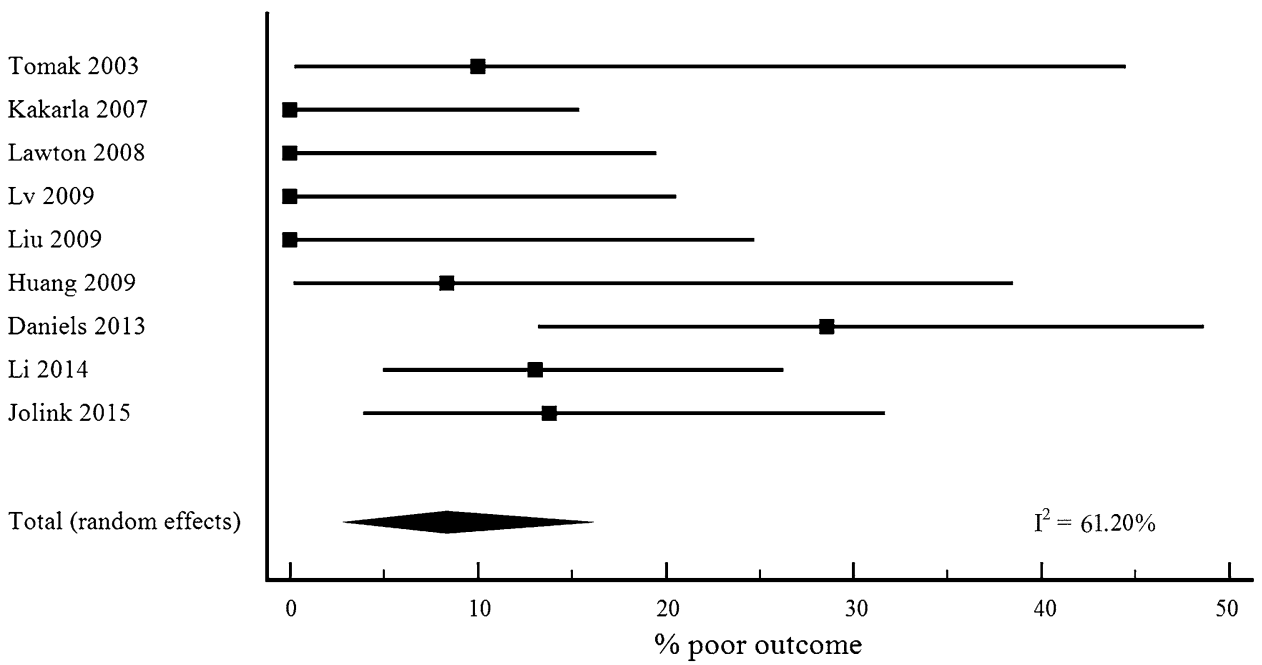

determine the cause of the intracranial haemorrhage may not always have been performed [31]. Also, DAVFs can be missed on CTA or MRA [32]. A further explanation may be that in contrast to the study that compared outcomes after AVM and spontaneous ICH [8], the cohorts in our study did not restrict inclusion to patients with $\mathrm{ICH}$ but included patients with SAH, IVH and SDH as well.

A possibly better clinical outcome from DAVFs in comparison with outcome after spontaneous or AVM-related ICH may be explained by the bleeding site of the ruptured DAVF being venous rather than arterial [26]. Several studies showed that intracranial haemorrhage due to a DAVF is related with cortical venous reflux, venous hypertension and venous congestion [7, 33-35]. Location of the DAVF-related haemorrhage being less often deep may also explain a better clinical outcome [36].

A strength of our study is that by combining the cohorts of two university medical centers and an overview of the current literature, we were able to study a relatively large number of patients given the rarity of this disease and study determinants of outcome. Also, we included patients irrespective of whether they had been treated or not, avoiding the selection mechanisms of some of the previous studies [18-23, 25]. Our study also has limitations. Limitations of our literature search are that none of the included studies fulfilled all our criteria of high quality. Second, outcome in the review includes the effects of treatment and is described over varying durations of follow-up. Furthermore, designs of included studies were heterogeneous, so results need to be interpreted with caution. Third, studies were not always restricted to patients who had presented with intracranial haemorrhage. Ten of the sixteen cohorts described patients treated by a specific modality, most certainly resulting in selection by indication. Also, different ways of reporting functional outcome were used.
Our study has implications for clinical practice. The outcome after the rupture of a DAVF can be used to inform patients and their relatives. Furthermore, our findings should be taken into account when weighing risks and benefits of treatment in patients with unruptured DAVFs. Studies of large patient cohorts, preferably prospective and population based, should give more precise estimates of the risk of poor outcome after DAVF-related intracranial haemorrhage and of factors that may determine outcome.

Acknowledgments Dr CJM Klijn is supported by a clinical established investigator grant [grant number 2012 T077] and a project grant from the Dutch Heart Foundation [grant number 2007B048] and an Aspasia grant from ZonMw [grant number 015008048].

\section{Compliance with ethical standards}

Conflicts of interest On behalf of all authors, the corresponding author states that there is no conflict of interest.

Ethical standard The Medical Ethics Review Committee of the University Medical Center Utrecht reviewed the protocol and waived the requirement for ethical review.

Open Access This article is distributed under the terms of the Creative Commons Attribution 4.0 International License (http://crea tivecommons.org/licenses/by/4.0/), which permits unrestricted use, distribution, and reproduction in any medium, provided you give appropriate credit to the original author(s) and the source, provide a link to the Creative Commons license, and indicate if changes were made.

\section{References}

1. Al-Shahi R, Bhattacharya JJ, Currie DG, Papanastassiou V, Ritchie V, Roberts RC et al (2003) Prospective, population-based detection of intracranial vascular malformations in adults: the Scottish Intracranial Vascular Malformation Study (SIVMS). Stroke 34:1163-1169 
2. Newton TH, Cronqvist S (1969) Involvement of dural arteries in intracranial arteriovenous malformations. Radiology 93:1071-1078

3. Davies MA, TerBrugge K, Willinsky R, Coyne T, Saleh J, Wallace MC (1996) The validity of classification for the clinical presentation of intracranial dural arteriovenous fistulas. J Neurosurg 85:830-837

4. Borden JA, Wu JK, Shucart WA (1995) A proposed classification for spinal and cranial dural arteriovenous fistulous malformations and implications for treatment. J Neurosurg 82:166-179

5. Cognard C, Gobin YP, Pierot L, Bailly AL, Houdart E, Casasco A et al (1995) Cerebral dural arteriovenous fistulas: clinical and angiographic correlation with a revised classification of venous drainage. Radiology 194:671-680

6. Peng T, Liu A, Jia J, Jiang C, Li Y, Wu Z et al (2014) Risk factors for dural arteriovenous fistula intracranial hemorrhage. J Clin Neurosci 21:769-772

7. Kobayashi A, Al-Shahi Salman R (2014) Prognosis and treatment of intracranial dural arteriovenous fistulae: a systematic review and meta-analysis. Int J Stroke 9:670-677

8. van Beijnum J, Lovelock CE, Cordonnier C, Rothwell PM, Klijn CJ, Al-Shahi Salman R et al (2009) Outcome after spontaneous and arteriovenous malformation-related intracerebral haemorrhage: population-based studies. Brain 132:537-543

9. Liberati A, Altman DG, Tetzlaff J, Mulrow C, Gotzsche PC, Ioannidis JP et al (2009) The PRISMA statement for reporting systematic reviews and meta-analyses of studies that evaluate healthcare interventions: explanation and elaboration. BMJ. doi:10.1136/bmj.b2700

10. Awad IA, Little JR, Akarawi WP, Ahl J (1990) Intracranial dural arteriovenous malformations: factors predisposing to an aggressive neurological course. J Neurosurg 72:839-850

11. Geibprasert S, Pereira V, Krings T, Jiarakongmun P, Toulgoat F, Pongpech S, Lasjaunias P (2008) Dural arteriovenous shunts: a new classification of craniospinal epidural venous anatomical bases and clinical correlations. Stroke 39:2783-2794

12. Hemphill JC, Bonovich DC, Besmertis L, Manley GT, Johnston SC (2001) The ICH score: a simple, reliable grading scale for intracerebral hemorrhage. Stroke 32:891-897

13. Kothari RU, Brott T, Broderick JP, Barsan WG, Sauerbeck LR, Zuccarello $\mathrm{M}$ et al (1996) The ABCs of measuring intracerebral hemorrhage volumes. Stroke 27:1304-1305

14. Newman GC (2007) Clarification of abc/2 rule for ICH volume. Stroke 38:862

15. Duffau H, Lopes M, Janosevic V, Sichez JP, Faillot T, Capelle L et al (1999) Early rebleeding from intracranial dural arteriovenous fistulas: report of 20 cases and review of the literature. J Neurosurg 90:78-84

16. Tomak PR, Cloft HJ, Kaga A, Cawley CM, Dion J, Barrow DL (2003) Evolution of the management of tentorial dural arteriovenous malformations. Neurosurgery 52:750-762

17. Van Rooij WJ, Sluzewski M, Beute GN (2007) Dural arteriovenous fistulas with cortical venous drainage: incidence, clinical presentation, and treatment. Am J Neuroradiol 28:651-655

18. Kakarla UK, Deshmukh VR, Zabramski JM, Albuquerque FC, McDougall CG, Spetzler RF (2007) Surgical treatment of highrisk intracranial dural arteriovenous fistulae: clinical outcomes and avoidance of complications. Neurosurgery 61:447-457

19. Lawton MT, Sanchez-Mejia RO, Pham D, Tan J, Halbach VV (2008) Tentorial dural arteriovenous fistulae: operative strategies and microsurgical results for six types. Neurosurgery 62:110-124

20. Cognard C, Januel AC, Silva NA Jr, Tall P (2008) Endovascular treatment of intracranial dural arteriovenous fistulas with cortical venous drainage: new management using onyx. Am J Neuroradiol 29:235-241
21. Lv X, Jiang C, Zhang J, Li Y, Wu Z (2009) Complications related to percutaneous transarterial embolization of intracranial dural arteriovenous fistulas in 40 patients. Am J Neuroradiol 30:462-468

22. Liu JK, Dogan A, Ellegala DB, Carlson J, Nesbit GM, Barnwell SL et al (2009) The role of surgery for high-grade intracranial dural arteriovenous fistulas: importance of obliteration of venous outflow. J Neurosurg 110:913-920

23. Huang Q, Xu Y, Hong B, Li Q, Zhao W, Liu J (2009) Use of Onyx in the management of tentorial dural arteriovenous fistulae. Neurosurgery 65:287-292

24. Guedin P, Gaillard S, Boulin A, Condette-Auliac S, Bourdain F, Guieu $S$ et al (2010) Therapeutic management of intracranial dural arteriovenous shunts with leptomeningeal venous drainage: report of 53 consecutive patients with emphasis on transarterial embolization with acrylic glue: clinical article. J Neurosurg 112:603-610

25. Wachter D, Hans F, Psychogios MN, Knauth M, Rohde V (2011) Microsurgery can cure most intracranial dural arteriovenous fistulae of the sinus and non-sinus type. Neurosurg Rev 34:337-345

26. Daniels DJ, Vellimana AK, Zipfel GJ, Lanzino G (2013) Intracranial hemorrhage from dural arteriovenous fistulas: clinical features and outcome. Neurosurg Focus. doi:10.3171/2013.4. FOCUS1335

27. Eftekhar B, Morgan MK (2013) Surgical management of dural arteriovenous fistulas of the transverse-sigmoid sinus in 42 patients. J Clin Neurosci 20:532-535

28. Li C, Yang X, Li Y, Jiang C, Wu Z (2014) Endovascular treatment of intracranial dural arteriovenous fistulas presenting with intracranial hemorrhage in 46 consecutive patients: with emphasis on transarterial embolization with onyx. Clin Neuroradiol. doi:10.1007/s00062-014-0362-y

29. Chandra RV, Leslie-Mazwi TM, Mehta BP, Yoo AJ, Rabinov JD, Pryor JC et al (2014) Transarterial onyx embolization of cranial dural arteriovenous fistulas: long-term follow-up. AJNR Am J Neuroradiol 35:1793-1797

30. Al-Mahfoudh R, Kirollos R, Mitchell P, Lee M, Nahser H, Javadpour M (2015) Surgical disconnection of the cortical venous reflux for high-grade intracranial dural arteriovenous fistulas. World Neurosurg 83:652-656

31. Cordonnier C, Klijn CJ, van Beijnum J, Al-Shahi Salman R (2010) Radiological investigation of spontaneous intracerebral hemorrhage: systematic review and trinational survey. Stroke 41:685-690

32. Brown RD Jr, Flemming KD, Meyer FB, Cloft HJ, Pollock BE, Link ML (2005) Natural history, evaluation, and management of intracranial vascular malformations. Mayo Clin Proc 80:269-281

33. van Dijk JM, terBrugge KG, Willinsky RA, Wallace MC (2002) Clinical course of cranial dural arteriovenous fistulas with longterm persistent cortical venous reflux. Stroke 33:1233-1236

34. Soderman M, Pavic L, Edner G, Holmin S, Andersson T (2008) Natural history of dural arteriovenous shunts. Stroke 39:1735-1739

35. Bulters DO, Mathad N, Culliford D, Millar J, Sparrow OC (2012) The natural history of cranial dural arteriovenous fistulae with cortical venous reflux-the significance of venous ectasia. Neurosurgery 70:312-319

36. Cordonnier C, Al-Shahi Salman R, Bhattacharya JJ, Counsell CE, Papanastassiou V, Ritchie V et al (2008) Differences between intracranial vascular malformation types in the characteristics of their presenting haemorrhages: prospective, population-based study. J Neurol Neurosurg Psychiatry 79:47-51 